\title{
RELEKSI FUNGSI LAHAN TERHADAP BIODIVERSITAS TUMBUHAN DI DAERAH ALIRAN SUNGAI CILAJA, UJUNG BERUNG
}

\author{
Hertien Koosbandiah Surtikanti ${ }^{1}$, Wahyu Surakusumah ${ }^{2}$, Tina Safaria ${ }^{3}$, Afri Irawan ${ }^{\text {b }}$ \\ Amelia Qadaryanti ${ }^{\mathrm{b}}$ \\ ${ }^{1,2,3}$ Program Studi Biologi, Departemen Pendidikan Biologi, FPMIPA UPI \\ email: ${ }^{1}$ hertien_surtikanti@yahoo.com
}

Diterima :12 Oktober 2016 Ditinjau : 28 Oktober 2016 Disetujui :25 November 2016

\begin{abstract}
Abstrak. Ketergantungan manusia terhadap lahan sangat terlihat nyata dengan adanya perubahan fungsi lahan. Perubahan fungsi lahan juga berdampak terhadap tingkat biodiversitas tumbuhan. Studi ini mempelajari tingkat biodiversitas dan kelimpahan tumbuhan di tiga lokasi yang berbeda yaitu lahan konservasi pinus/perkebunan kopi, lahan persawahan dan lahan pemukiman. Ketiga lahan tersebut berada di Daerah Aliran Sungai (DAS) Cilaja yaitu di Desa Giri Mekar dan Desa Sindanglaya Kabupaten Bandung. Dalam penelitian ini dilakukan metode sampling struktur komunitas vegetasi untuk mengetahui komposisi, struktur dan jenis vegetasi serta perbedaan komunitas di tiga titik lokasi tersebut. Untuk analisis kuantitatif digunakan metode kuadran. Hasil penelitian menunjukkan bahwa lahan pemukiman desa lebih beragam dibandingkan dengan lahan sawah dan lahan perkebunan kopi. Dapat disimpulkan secara umum bahwa keterlibatan dalam mengelola lahan dapat merubah komunitas, tingkat keanekaragaman dan dominansi tumbuhan.

Kata kunci : DAS, tingkat biodiversitas, metode sampling struktur komunitas vegetasi

Abstract. Human dependence on land is very evident with the change in land use. Changes in land use also have an impact on the level of plant biodiversity. The study followed the level of biodiversity and abundance of plants in three different locations namely conservation land pine / coffee plantations, rice fields and residential land. The third land is located in the Watershed (DAS) Cilaja is in the village of Giri Mekar and Rural Sindanglaya Bandung regency. In this research, community structure vegetation sampling methods to determine the composition, structure and type of vegetation and the three-point difference in the communities that location. For quantitative analysis used kuadran method. The results showed that the rural residential land is more diverse than the wetland and coffee plantation. In general it can be concluded that involvement in land management can change the community, the level of diversity and dominance of plants.
\end{abstract}

Keywords : DAS, level of biodiversity, community structure vegetation sampling methods

\section{PENDAHULUAN}

Pertumbuhan jumlah penduduk dan kebutuhan penduduk dalam meningkatkan taraf hidup menyebabkan adanya ketergantungan terhadap sumber daya lahan. Daerah Aliran Sungai Cilaja merupakan sungai yang memiliki fungsi yang beragam dan merupakan sumber kehidupan bagi masyarakat yang tinggal di daerah tersebut. Adanya fungsi lahan yang berbeda di sepanjang DAS Cilaja jika tidak dikelola dengan baik dapat merusak kondisi tanah dan mengurangi kualitas air DAS Cilaja. Rahayu, et. al. (2009) menyatakan bahwa sistem penggunaan lahan dengan penanaman tumbuhan tertentu dapat berdampak terhadap kondisi lahan dan kualitas sungai. Jenis tutupan lahan dapat mempertahankan kestabilan tanah serta menghindari erosi. Dengan adanya peruntukan lahan yang berbeda dan ditunjang dengan faktor abiotik lingkungan menyebabkan keanekaragaman tumbuhan yang berbeda di DAS Cilaja.

\section{BAHAN DAN METODE}


Penelitian deskriptif ini (Nazir, 1988) dilakukan di DAS Cilaja, Desa Giri Mekar dan Desa Sindanglaya Kabupaten Bandung. Pengambilan sampel dilakukan di tiga lokasi (Gambar 1) yaitu lokasi bagian hulu sungai yang berada di lahan konservasi pinus dan perkebunan kopi; lokasi tengah yang berada di area persawahan; dan lokasi hilir yang berada disekitar pemukiman penduduk. Penentuan ketiga lokasi tesebut berdasarkan hasil survey sebelumnya yang dilakukan berdasarkan kriteria kelayakan dari akses, keamanan dan keberadaan aspek biologi.

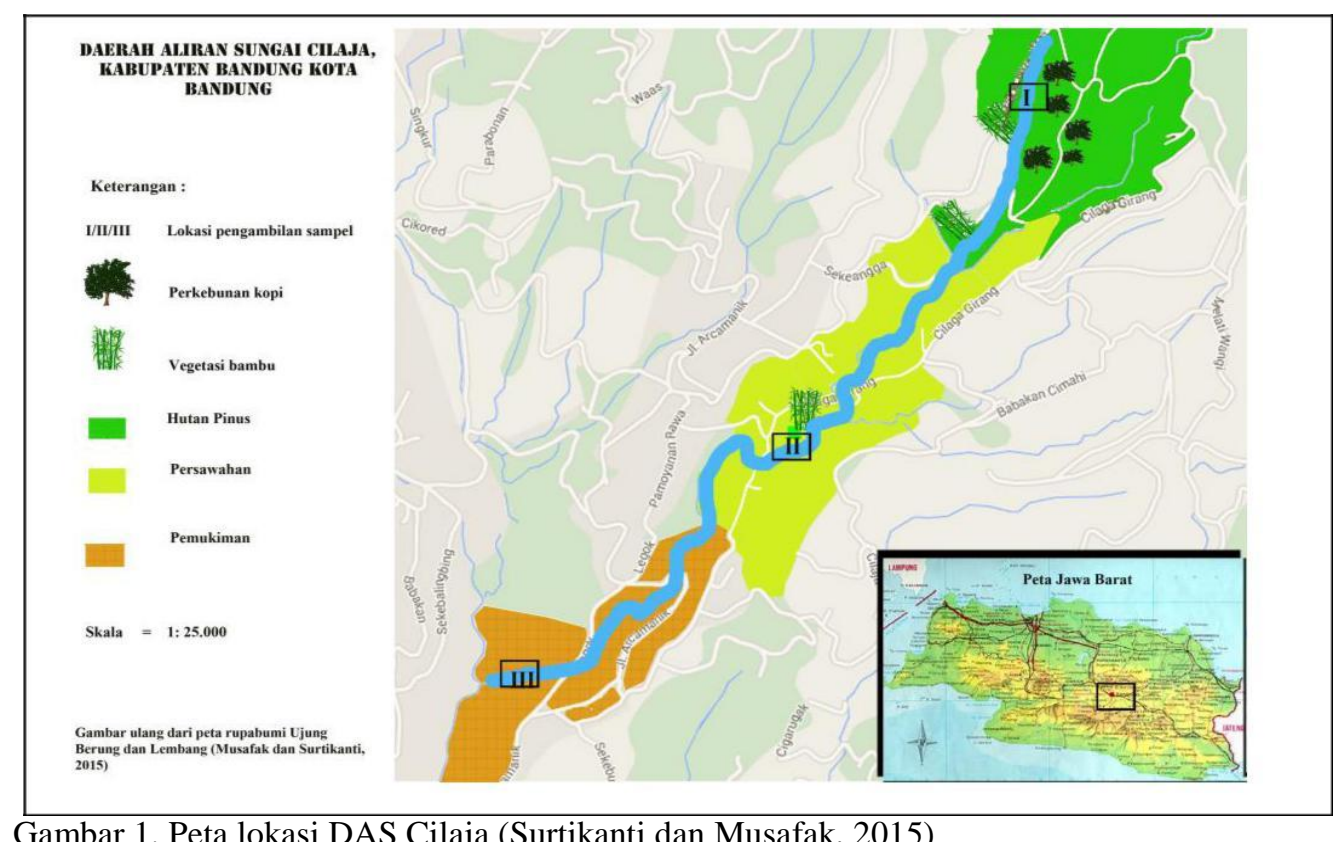

Gambar 1. Peta lokasi DAS Cilaja (Surtikanti dan Musafak, 2015)

Teknik pengambilan sampel vegetasi pada penelitian ini menggunakan metode kuadran. Pengamatan dan pengambilan sampel dilakukan di dalam kuadran tersebut (Phillpis, 1959). Penelitian ini menggunakan 9 unit kuadran, dengan masing-masing lokasi memiliki 3 unit kuadran. Setiap unit kuadran berukuran $20 \times 20 \mathrm{~m}$ untuk mengambil sampel tumbuhan jenis pohon, kemudian di dalam kuadran tersebut dibuat kuadran berukuran $5 \mathrm{x}$ $5 \mathrm{~m}$ untuk mengambil sampel tumbuhan jenis semak, dan di dalamnya dibuat kuadran berukuran 1 x $1 \mathrm{~m}$ untuk mengambil sampel tumbuhan jenis herba (Gambar 2). Kuadran tersebut dipasang ditepi sungai dengan jarak setiap kuadran sejauh $20 \mathrm{~m}$. Posisi antar kuadran tersebut diposisikan secara berseling pada setiap kanan dan kiri sungai. Dilakukan pengamatan dan penghitungan sampel tumbuhan di dalam kuadran yang telah dibuat. Penamaan jenis tumbuhan diidentifikasi hingga tingkat species.

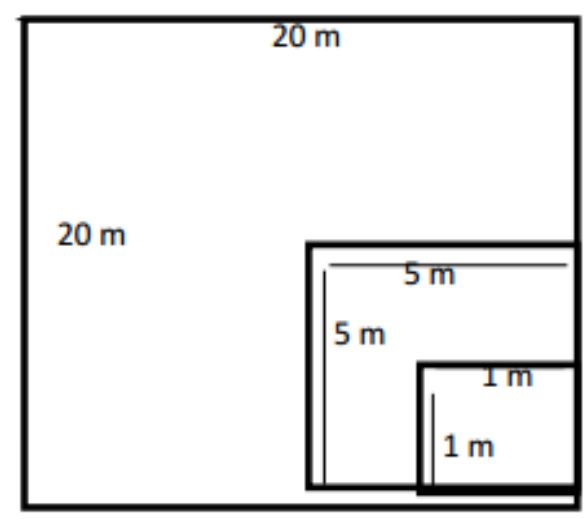

Gambar 2. Desain setiap kuadrat penelitian

Pengolahan data terhadap jumlah tumbuhan dilakukan dengan 2 penghitungan yaitu (a) nilai indeks keanekaragaman dan (b) nilai kelimpahan jumlah individu setiap spesies. Penghitungan nilai indeks keanekaragaman untuk tiap jenis herba, semak, dan pohon, dilakukan dengan menggunakan rumus indeks keanekaragaman Shannon-Wiener (Michael, 1984). Rumus yang digunakan adalah sebagai berikut: 
$\mathbf{H}^{\prime}=-\sum \boldsymbol{P i} \ln \boldsymbol{P} ;$; dimana, $P \boldsymbol{i}=\mathrm{ni} / \mathrm{N}$

H': Indeks keanekaragaman Shannon-Wiener

Pi: perbandingan jumlah individu suatu jenis dengan jumlah individu keseluruhan sampel dalam plot.

ni: jumlah individu dari suatu jenis $i$.

$\mathrm{N}$ : jumlah total individu.
Sedangkan untuk mengetahui kelimpahan jumlah individu setiap spesies tumbuhan yang ditemukan menggunakan rumus kelimpahan sebagai berikut:

$\boldsymbol{P} \boldsymbol{i}=\frac{\sum \text { species } i}{\sum \text { total seluruh individu }}$

$P i$ : Nilaikelimpahan species $i$
Nilai indeks keanekaragaman Shannon Wiener didefinisikan sebagai berikut (Fachrul, 2012):

1. Nilai $H^{\prime}<1$ menunjukkan keanekaragaman species rendah.

2. Nilai $H^{\prime} 1 \leq \mathrm{H}^{\prime} \leq 3$ menunjukkan keanekaragaman species sedang.

3. Nilai $H^{\prime}>3$ menunjukkan keanekaragaman spesies tinggi.

\section{HASIL}

Hasil yang akan dipaparkan berdasarkan tabel 1 diantaranya meliputi rona lingkungan DAS Cilaja, dan keanekaragaman serta kelimpahan tumbuhan (herba, semak dan pohon) di 3 lokasi DAS Cilaja.

Tabel 1. Rona lingkungan DAS Cilaja

\begin{tabular}{|c|c|c|c|c|}
\hline No. & Kriteria & Wilayah 1 & Wilayah 2 & Wilayah 3 \\
\hline 1 & Fungsi lahan & $\begin{array}{c}\text { Perkebunan Kopi dan } \\
\text { Hutan Alami Pinus }\end{array}$ & Pesawahan & Pemukiman \\
\hline 2 & Kecepatan air $(\mathrm{m} / \mathrm{s})$ & 0,16 & 0.22 & 0.24 \\
\hline 3 & Kedalaman (m) & 0.4 & 0.5 & 0.5 \\
\hline 4 & $\begin{array}{l}\text { Luas penampang } \\
\qquad\left(\mathrm{m}^{2}\right)\end{array}$ & 0.24 & 0.49 & 0.75 \\
\hline 5 & Debit air $\left(\mathrm{m}^{3} / \mathrm{s}\right)$ & 0.038 & 0.24 & 0.18 \\
\hline 6 & Jenis substrat & Batuan dan pasir & Batuan dan pasir & Batuan dan pasir \\
\hline 7 & Kondisi sungai & Tidak berbau & Tidak berbau & Tidak berbau \\
\hline 8 & $\begin{array}{c}\text { Penggunaan lahan } \\
\text { dan rona } \\
\text { lingkungan }\end{array}$ & $\begin{array}{l}\text { Perkebunan kopi, } \\
\text { Pinus, Bamboosa sp, } \\
\text { Musa paradisiaca, } \\
\text { Calliandra sp, } \\
\text { tumbuhan paku }\end{array}$ & $\begin{array}{c}\text { Pesawahan } \\
\text { ( Oryza sativa), } \\
\text { Musa paradisiaca, }, \\
\text { Manihot } \\
\text { esculenta, } \text { Sintrong }\end{array}$ & $\begin{array}{l}\text { Pemukiman } \\
\text { Warga } \\
\text { Musa } \\
\text { paradisiaca, } \\
\text { Bamboosa sp, } \\
\text { Calliandra sp }\end{array}$ \\
\hline 9 & Koordinat & $\begin{array}{c}\text { S: } 06.86280^{\circ} \\
\text { E: } 107.709660^{\circ}\end{array}$ & $\begin{array}{l}\text { S: } 06.87684^{0} \\
\text { E: } 107.6969^{0}\end{array}$ & $\begin{array}{l}\text { S: } 06.87959^{0} \\
\text { E: } 107.69225^{0}\end{array}$ \\
\hline 10 & Ketinggian & $1212 \mathrm{~m}$ & $934 \mathrm{~m}$ & $909 \mathrm{~m}$ \\
\hline 11 & $\begin{array}{c}\text { Jarak Antar Lokasi } \\
\text { Penelitian }\end{array}$ & $\begin{array}{c}5 \mathrm{~km} \text { dari lokasi } \\
\text { Pertanian }\end{array}$ & $\begin{array}{l}2 \mathrm{~km} \text { dari lokasi } \\
\text { Pemukiman }\end{array}$ & $\begin{array}{c}6 \text { km dari jalan } \\
\text { Raya }\end{array}$ \\
\hline
\end{tabular}

Hasil penelitian pada tabel di bawah ini menampilkan data keanekaragaman dan nilai kelimpahan tumbuhan untuk jenis herba
(Tabel 2), semak (Tabel 3) dan pohon (Tabel 4) pada masing-masing fungsi lahan yang berbeda.

Tabel 2.Daftar tumbuhan jenis herba di 3 lokasi DAS Cilaja dengan jumlah dan nilai kelimpahan

\begin{tabular}{ccccc}
\hline No. & Nama Species & $\mathbf{1}$ & $\mathbf{2}$ & $\mathbf{3}$ \\
\hline 1 & Acmella uliginosa & $\mathbf{1 7 / 0 , 0 9}$ & $6 / 0,04$ & $6 / 0,03$ \\
2 & Ageratina riparia & $6 / 0,03$ & 0 & 0 \\
3 & Ageratum conyzoides & $11 / 0.06$ & $5 / 0,03$ & $3 / 0,02$ \\
4 & Alocasia macrorrhizos & 0 & 0 & $3 / 0,02$ \\
5 & Alternanthera sp. & $\mathbf{0}$ & $\mathbf{0}$ & $\mathbf{7 / 0 , 0 4}$ \\
6 & Bidens pilosa & $\mathbf{1 4 / 0 , 0 8}$ & 0 & 0 \\
7 & Centrosema molle & 0 & $4 / 0,03$ & 0 \\
8 & Centella asiatica & $\mathbf{1 4 / 0 , 0 8}$ & 0 & 0 \\
9 & Commelina diffusa & 0 & 0 & $9 / 0,06$ \\
10 & Curculigo capitulata & $1 / 0,005$ & 0 & 0 \\
11 & Cyperus rotundus & $4 / 0,02$ & 0 & 0 \\
12 & Cyrtococcum sp. & 0 & $4 / 0,03$ & 0 \\
\hline
\end{tabular}




\begin{tabular}{lcccc}
\hline 13 & Dieffenbachia seguine & 0 & 0 & $7 / 0,04$ \\
14 & Digitaria didactyla & $10 / 0,05$ & $\mathbf{3 0 / 0 , 2 2}$ & 0 \\
15 & Drymaria cordata & 0 & $15 / 0,11$ & $13 / 0,08$ \\
16 & Eragrostis sp. & 0 & 0 & $10 / 0,06$ \\
17 & Galinsoga parviflora & $\mathbf{1 3 / 0 , 0 7}$ & 0 & 0 \\
18 & Impatiens walleriana & $2 / 0,011$ & 0 & $3 / 0,02$ \\
19 & Imperata cylindrica & 0 & $6 / 0,04$ & 0 \\
20 & Peperomia pellucida & 0 & 0 & $2 / 0,01$ \\
21 & Mimosa pudica & $\mathbf{0}$ & $\mathbf{1 1 / 0 , 0 8}$ & 0 \\
22 & Oxalis corniculata & $6 / 0,03$ & 0 & 0 \\
23 & Paspalum sp & $\mathbf{2 0 / 0 , 1 1}$ & $4 / 0,02$ & 0 \\
24 & Pennisetum purpureum & 0 & $10 / 0,07$ & 0 \\
25 & Plantago major & $5 / 0,02$ & 0 & $3 / 0,02$ \\
26 & Polygala paniculata & $5 / 005$ & 0 & 0 \\
27 & Sida acuta & $2 / 0,01$ & $3 / 0,02$ & 0 \\
28 & Sphagneticola trilobata & 0 & $24 / 0,18$ & $18 / 0,11$ \\
29 & Synedrella nodiflora & 0 & $2 / 0,01$ & $\mathbf{5 2 / 0 , 3 3}$ \\
30 & Syngonium sp. & 0 & $10 / 0,07$ & $20 / 0,13$ \\
31 & Setaria barbata & $\mathbf{2 8}$ & 0 & 0 \\
32 & Solanum sp. & $1 / 0,005$ & 0 & 0 \\
33 & Stachytarpheta jamaicensis & $1 / 0,005$ & 0 & 0 \\
34 & Synedrella nodiflora & $\mathbf{1 3 / 0 , 0 0 5}$ & 0 & 0 \\
& Jumlah & $\mathbf{1 7 4}$ & $\mathbf{1 3 4}$ & $\mathbf{1 5 6}$ \\
& H' (Index Keanekaragaman) & $\mathbf{2 , 6 4}$ & $\mathbf{2 , 3 4}$ & $\mathbf{2 , 1 9}$ \\
\hline \multicolumn{7}{r}{} & & & &
\end{tabular}

Tabel 3. Daftar tumbuhan jenis semak di 3 lokasi DAS Cilaja dengan jumlah dan nilai kelimpahan

\begin{tabular}{clccc}
\hline No. & \multicolumn{1}{c}{ Nama Species } & $\mathbf{1}$ & $\mathbf{2}$ & $\mathbf{3}$ \\
\hline 1 & Calliandra calothyrsus & $\mathbf{1 2 / 0 , 1 9}$ & 0 & 0 \\
2 & Calliandra portoricensis & $2 / 0,03$ & $5 / 0,08$ & $2 / 0,13$ \\
3 & Clidemia hirta & $5 / 0,08$ & 0 & 0 \\
4 & Eupatorium inulifolium & $\mathbf{2 2 / 0 , 3 5}$ & $13 / 0,22$ & 0 \\
5 & Lantana camara & $7 / 0,11$ & $7 / 0,12$ & $7 / 0,47$ \\
6 & Malvaviscus arboreus & 0 & 0 & $\mathbf{5 / 0 , 3 3}$ \\
7 & Mimosa pigra & 0 & $3 / 0,05$ & 0 \\
8 & Moringa oleifera & $1 / 0,02$ & 0 & 0 \\
9 & Pennisetum purpureum & $\mathbf{1 3 / 0 , 2 1}$ & 0 & 0 \\
10 & Platostoma sp. & 0 & $\mathbf{1 4 / 0 , 2 3}$ & 0 \\
& Strobilanthes crispa & 0 & 0 & $1 / 0,02$ \\
11 & Tithonia diversifolia & 0 & $18 / 0,30$ & 0 \\
& Jumlah & $\mathbf{6 2}$ & $\mathbf{6 0}$ & $\mathbf{1 5}$ \\
& H' (Index Keanekaragaman) & $\mathbf{1 , 6 4}$ & $\mathbf{1 , 6 4}$ & $\mathbf{1 , 1 7}$ \\
\hline
\end{tabular}

Tabel 4.Daftar tumbuhan jenis pohon di 3 lokasi DAS Cilaja dengan jumlah dan nilai kelimpahan

\begin{tabular}{|c|c|c|c|c|}
\hline No. & Nama Species & 1 & 2 & 3 \\
\hline 1 & Alstonia scholaris & $1 / 0,02$ & 0 & 0 \\
\hline 2 & Arenga pinnata & $6 / 0,12$ & 0 & 0 \\
\hline 3 & Artocarpus heterophyllus & $4 / 0,08$ & 0 & 0 \\
\hline 4 & Bambusa heterostachya & 0 & 0 & $35 / 0,61$ \\
\hline 5 & Bambusa sp & 0 & 0 & $12 / 0,21$ \\
\hline 6 & Ficus carica & 0 & 0 & $1 / 0,02$ \\
\hline 7 & Hibiscus tiliaceus & 0 & $5 / 0,30$ & $2 / 0,03$ \\
\hline 8 & Homalanthus populneus & 0 & 0 & $1 / 0,02$ \\
\hline 9 & Persea americana & $3 / 0,06$ & 0 & 0 \\
\hline 10 & Pinus merkusii & $31 / 0,63$ & 0 & 0 \\
\hline 11 & Pterospermum sp. & 0 & 0 & $2 / 0,03$ \\
\hline 12 & Ricinus communis & $3 / 0,06$ & 0 & 0 \\
\hline 13 & Swietenia mahogony & $1 / 0,02$ & $2 / 0,12$ & 0 \\
\hline 14 & Syzygium aqueum & 0 & $6 / 0,35$ & $3 / 0,05$ \\
\hline \multirow[t]{3}{*}{15} & Toona sureni & 0 & $4 / 0,23$ & $1 / 0,02$ \\
\hline & Jumlah & 49 & 17 & 57 \\
\hline & H' (Index Keanekaragaman) & 1,25 & 1,32 & 1,23 \\
\hline
\end{tabular}




\section{PEMBAHASAN}

Perbedaan rona lingkungan (Tabel 1) antara daerah hulu, persawahan, dan hilir menjadikan kawasan DAS Cilaja menjadi beragam. Mulai dari keragaman struktur tanah, cuaca di lokasi, daerah sungai yang berbeda, sampai kegiatan masyarakat yang berbeda pula. Lingkungan dan manusia merupakan satu kesatuan yang tidak dapat dipisahkan dan keduanya memiliki hubungan timbal balik. Lingkungan yang terbentuk merupakan produk dari hasil aktifitas manusia (Sangalang dan Adji 2014). Keterlibatan manusia dalam mengolah lingkungan umumnya merupakan suatu lingkungan binaan.

Faktor geografis juga dapat memberikan kontribusi terhadap bentuk suatu lahan. Dalam penelitian ini terdapat 3 lahan yang menunjukkan perbedaan rona lingkungan. Bagian hulu DAS adalah suatu wilayah daratan bagian dari DAS yang dicirikan dengan topografi bergelombang, berbukit dan atau bergunung, kerapatan drainase relatif tinggi, merupakan sumber air yang masuk ke sungai utama dan sumber erosi yang sebagian terangkut menjadi sedimen daerah hilir. Daerah hulu tidak diketemukan pemukiman penduduk. Kemiringan lereng merupakan faktor lain yang mempengaruhi keadaan suatu jenis lahan (Saribun 2007). Dikatakan pula bahwa Wilayah DAS bagian hulu yang terletak di dataran tinggi pada umumnya didominasi oleh lahan dengan kemiringan lereng di atas 15\%. Sehingga lahan tersebut berpotensi mengalami erosi yang besar. Oleh sebab itu untuk menjaga keberlangsungan ekosistem dan keamanan dari bencana bagi daratan bagian hilir DAS Cilaja, maka dilakukan konservasi pinus dan kebun kopi. DAS bagian hulu umumnya difungsikan dalam bentuk konservasi untuk pertahanan kondisi lingkungan (Caya 2014).

Bagian tengah DAS adalah suatu wilayah bagian dari DAS yang dicirikan dengan topografi datar. Di daerah lahan ini cocok untuk sawah dan tumbuhan sayuran. Topografi yang datar ini memungkinan adanya bangunan pemukiman. Sedangkan bagian hilir DAS adalah suatu wilayah daratan bagian dari DAS yang dicirikan dengan topografi datar sampai landai, merupakan daerah endapan sedimen atau aluvial. Bagian ini medekati daerah urban, dan akses menuju lokasi ini sangat mudah. Sehingga memungkinan adanya perumahan penduduk yang lebih padat dibandingkan di lahan pertanian.

Rona lingkungan dan keterlibatan manusia dalam mengelola ke tiga lingkungan tersebut berdampak terhadap keanekaragaman biota, khususnya vegetasi. Struktur vegetasi merupakan salah satu komponen penting dalam ekosistem DAS. Wikantika, et al. (2005) mengatakan bahwa vegetasi lahan hijau sekitar DAS merupakan komponen penyangga erosi dan kekeringan.

\section{Tumbuhan Jenis Herba}

Berdasarkan Tabel 2, ditemukan 34 jenis herba di DAS Cilaja yang diamati dan nilai indeks keanekaragaman Shannon-Wiener $\left(\mathrm{H}^{\prime}\right)$ tumbuhan jenis herba berturut-turut dilokasi 1 , 2 dan 3 adalah 2,64; 2,34; dan 2,19. Nilai indeks tersebut menunjukkan keanekaragaman tumbuhan jenis herba katagori sedang pada ketiga lokasi. Walaupun nilai index keanekaragaman tumbuhan herba termasuk ke dalam tingkat sedang, namun nilai index keanekaragaman tumbuhan herba berturutturut di daerah hulu, tengah dan hilir cenderung berkurang. Keberadaan tumbuhan herba sangat dibutuhkan di daerah hulu dan memiliki potensi dalam mempertahankan konservasi tanah dan air. Hal ini diperkuat dengan hasil kajian Maridi, et. al. (2014) bahwa Mimosa pudica, Ageratum conyzoides dan berbagai tumbuhan rumput lainnya memiliki potensi penting bagi koservasi DAS Samin. Selain itu pula vegetasi rumput dapat menahan limpasan dan memperbesar infiltrasi air kedalam tanah (Sancayanigsih dan Alanindra 2013).

Lokasi DAS Cilaja memperlihatkan dominansi dan keberadaan tumbuhan herba yang berbeda diantara fungsi lahan yang berbeda. Tumbuhan jenis herba yang hanya ditemukan dilokasi hulu yaitu: Ageratina riparia, Bidens pilosa, Centella asiatica, Galinsoga parviflora, Paspalum sp dan Setaria barbata. Sedangkan tumbuhan jenis herba yang hanya ditemukan di lokasi persawahan adalah Centrosema molle, 
Cyrtococcum sp. Imperata cylindrica, Mimosa pudica, dan Pennisetum purpureum. Tumbuhan jenis herba yang hanya ditemukan di lokasi pemukiman yaitu: Alocasia macrorrhizos, Alternanthera sp. Commelina diffus, dan Dieffenbachia seguine.

\section{Tumbuhan Jenis Semak}

Berdasarkan Tabel 3, nilai indeks keanekaragaman Shannon-Wiener (H') tumbuhan jenis semak dilokasi 1, 2 dan 3 berturut-turut adalah 1,64; 1,64; dan 1,17. Nilai indeks tersebut menunjukkan keanekaragaman tumbuhan jenis semak katagori sedang pada ketiga lokasi. Tumbuhan jenis semak dengan nilai Pi tertinggi adalah Eupatorium inulifolium yaitu sebesar 0,35. Nilai Pi tertinggi menunjukan bahwa species Eupatorium inulifolium memiliki kelimpahan tertinggi dilokasi pertama dengan jumlah 22 individu

\section{Tumbuhan Jenis Pohon}

Berdasarkan Tabel 4, nilai indeks keanekaragaman Shannon-Wiener (H') tumbuhan jenis pohon dilokasi 1, 2 dan 3 berturut-turut adalah 1,25; 1,32; dan 1,23. Nilai indeks tersebut menunjukkan keanekaragaman tumbuhan jenis pohon katagori sedang pada ketiga lokasi. Tetapi jenis pohon yang teramati di masing-masing lokasi berbeda. Di bagian hulu ditemukan pohon Alstonia scholaris, Arenga pinnata, Artocarpus heterophyllus, dan Pinus merkusii (paling dominan). Habitus pohon memiliki morfologi rangkaian pertumbuhan arsitekstur yang berbeda. Model arsitekstur pohon tertentu dapat mempengaruhi translokasi air hujan menjadi laju aliran batang, air tembus tajuk, infiltrasi dan laju aliran permukaan pada suatu area yang terkait dengan peranan vegetasi dalam mengurangi laju erosi di lokasi tersebut (Arrijani, et. al. 2006). Oleh sebab itu keberadaan 7 jenis pohon di daerah hulu DAS Cilaja memiliki peranan penting dalam mempertahankan konservasi ekosistem hutan.

Sedangkan di bagian tengah dan hilir ditemukan pohon yang sengaja ditanam oleh manusia seperti Syzygium aqueum (persawahan) dan Bambusa heterostachya (pemukiman). Hal ini menunjukkan bahwa keterlibatan manusia dalam mengelola lahan terlihat dengan menanam pohon yang dibutuhkan masyarakat.

Secara umum dapat disimpulkan bahwa DAS Cilaja memliki kelimpahan tumbuhan tertinggi untuk tingkat herba adalah species Synedrella nodiflora (jotang kuda), tingkat semak adalah Eupatorium inulidolium, dan tingkat pohon adalah species Bambusa heterstachya. Sedangkan masing-masing lokasi dapat disimpulkan juga bahwa kelimpahan tumbuhan tertinggi dilokasi pertama (konservasi) untuk tingkat herba adalah species Setaria barbata (Jukut jamarak), tingkat semak adalah Eupatorium inulidolium (kirinyuh) dan tingkat pohon adalah species Pinus merkusii. Kelimpahan tumbuhan tertinggi dilokasi kedua (persawahan) untuk tingkat herba adalah species Digitaria didactyla (Jukut siku), tingkat semak adalah Tithonia diversifolia (Kipait), dan tingkat pohon adalah species Syzygium aqueum (Jambu air). Kelimpahan tumbuhan tertinggi dilokasi ketiga (pemukiman) untuk tingkat herba adalah species Synedrella nodiflora (Jotang kuda), tingkat semak adalah Lantana camara (Saliara), dan tingkat pohon adalah species Bambusa heterostachya (Bambu).

\section{UCAPAN TERIMA KASIH}

Penelitian ini terlaksana atas dana hibah Penelitian Unggulan Perguruan Tinggi (DIKTI-UPI) Tahun 2016.

\section{DAFTAR PUSTAKA}

Arrijani, et. al. 2006. Analisa vegetasi hulu DAS Cianjur, Taman Nasional Gunung Gede Pangrango. Biodiversitas 7 (2): 147153.

Caya. 2014. Optimalisasi penggunaan lahan untuk agroforestri. Jurnal Teknosains 4 (1): 39-53.

Fachrul, M. F. 2012. Metode Sampling Bioekologi. Bumi Aksara. Jakarta.

Maridi, et. al. 2014. Vegetation analysis of Samin watershed, Central Java, as Water and soil conservation efforts. Biodiversitas journal of biological diversity 15(2): 215-223. 
Michael, P. 1984. Ecological Methods for Field and Laboratory Investigations. Tata McGraw-Hill Publishing Company Limited. New Delhi.

Nazir, M. 1988. MetodePenelitian. Ghalia Indonesia. Jakarta.

Phillips, E. A. 1959. Methods of Vegetation Study. Holt, Rinehart and Winston, Inc. Library of Congres Catalog Card Number 59-8736. United States of America

Rahayu, S., et. al. 2009. Monitoring air di daerah aliran sungai. World Agroforestry Centre Bogor.

Sancayanigsih, R. P. dan Alanindra, S. 2013. Analisis struktur vegetasi pohondi mata air yang berpotensi untuk konservasi mata air. Fakultas Biologi UGM. Jogjakarta.

Sangalang, I dan Adji, F. F. 2014. Pengaruh kondisi hunian dan lingkungan terhadap keberlanjutan pemukiman tepi sungai.
Studi kasus: Kampung Pahandut dan Desa Danau Tundai di kota Palangka Raya. Jurnal Perspektif Arsitektur 9 (2).

Saribun, D. 2007. Pengaruh Jenis Penggunaan Lahan dan Kelas Kemiringan LerengTerhadap Bobot Isi, Porositas Total, dan Kadar Air Tanah Pada SubDAS Cikapundung Hulu. Skripsi. Ilmu Tanah Fakultas Pertanian Universitas Padjadjaran Jatinangor.

Wikantika, K.A., et. al. 2005. Detection of vegetation change using Spectral Mixture Analisis from Multiremporal Data of Lansat-TM and ETM. Journal of Infrastructure and Built Environment 1 (2): 11-21. 